\title{
Long-term use of inhaled glucocorticoids in patients with stable chronic obstructive pulmonary disease and risk of bone fractures: a narrative review of the literature
}

This article was published in the following Dove Press journal:

International Journal of Chronic Obstructive Pulmonary Disease

\author{
Gaetano Caramori ${ }^{1}$ \\ Paolo Ruggeri' \\ Fabio Arpinelli ${ }^{2}$ \\ Laura Salvi ${ }^{2}$ \\ Giuseppe Girbino' \\ 'Unità Operativa Complessa di \\ Pneumologia, Dipartimento di Scienze \\ Biomediche, Odontoiatriche e delle \\ Immagini Morfologiche e Funzionali \\ (BIOMORF), Università degli Studi di \\ Messina, Messina, Italy; ${ }^{2}$ Direzione \\ Medica, GSK, Verona, Italy
}

\begin{abstract}
Patients with chronic obstructive pulmonary disease (COPD) demonstrate a greater osteoporosis prevalence than the general population. This osteoporosis risk may be enhanced by treatment with inhaled corticosteroids (ICSs), which are recommended for COPD management when combined with long-acting bronchodilators, but may also be associated with reduced bone mineral density (BMD). We conducted a narrative literature review reporting results of randomized controlled trials (RCTs) of an ICS versus placebo over a treatment period of at least 12 months, with the aim of providing further insight into the link between bone fractures and ICS therapy. As of 16 October 2017, we identified 17 RCTs for inclusion. The ICSs studied were budesonide (six studies), fluticasone propionate (five studies), mometasone furoate (three studies), beclomethasone dipropionate, triamcinolone acetonide, and fluticasone furoate (one each). We found no difference in the number of bone fractures among patients receiving ICSs versus placebo across the six identified RCTs reporting fracture data. BMD data were available for subsets of patients in few studies, and baseline BMD data were rare; where these data were given, they were reported for treatment groups without stratification for factors known to affect BMD. Risk factors for reduced BMD and fractures, such as smoking and physical activity, were also often not reported. Furthermore, a standardized definition of the term "fracture" was not employed across these studies. The exact relationship between long-term ICS use and bone fracture incidence in patients with stable COPD remains unclear in light of our review. We have, however, identified several limiting factors in existing studies that may form the basis of future RCTs designed specifically to explore this relationship.
\end{abstract}

Keywords: COPD, inhaled corticosteroids, osteoporosis, fracture risk

\section{Plain language summary}

Osteoporosis, a condition that causes bones to become fragile and prone to fracture, is more common in patients with chronic obstructive pulmonary disease (COPD) than the general population. In addition, inhaled corticosteroids (ICSs), which are recommended for COPD treatment alongside other agents, may also have a negative effect on bone strength and may further increase fracture risk for these patients. Previous studies looking at the association between ICS use and bone fracture risk have given mixed results, meaning that this potential relationship must be explored further. We present the results of a review of published studies of ICS versus placebo in patients with COPD lasting at least 12 months, with the hope of identifying further details of the ICS-bone fracture relationship. We found no difference in the fracture risk for patients receiving ICSs compared with those receiving placebo. Our
Correspondence: Fabio Arpinelli Direzione Medica, GSK, Via Alessandro Fleming 2, Verona 37I35, Italy Tel +39348 I307805

Email fabio.a.arpinelli@gsk.com 
review did, however, identify issues in the reporting of bone data in the studies we identified, including limited reporting of known risk factors for fractures (smoking, exercise) and a lack of a standard definition of the term "fracture" across the studies. Further research into the relationship between ICS treatment and bone fractures is needed to determine the potential impact for patients with COPD.

\section{Introduction}

Current national and international guidelines for the management of patients with chronic obstructive pulmonary disease (COPD) recommend maintenance therapy with inhaled long-acting bronchodilators (long-acting $\beta_{2^{-}}$ adrenergic agonists [LABAs] and long-acting muscarinic antagonists [LAMAs]), inhaled corticosteroids (ICSs), including glucocorticoids, and their combinations (usually LABA/ICS in one single inhaler at fixed dose) for the treatment of moderate-to-severe disease. ${ }^{1-5}$ In addition, patients with COPD may experience exacerbations requiring short-term treatment with systemic corticosteroids, ${ }^{2}$ which may increase their risk of developing osteoporosis through effects exerted on osteoclasts and osteoblasts. ${ }^{6}$ Coupled with the already increased prevalence of osteoporosis among patients with $\mathrm{COPD},{ }^{7}$ treatment with ICSs may substantially increase the risk of bone fractures in this patient population.

The skeletal effects of ICSs are not fully understood and existing studies provide conflicting results; however, most studies in patients with COPD receiving ICSs have not found a detrimental effect of these agents on bone. ${ }^{8}$ Our understanding of this topic is hindered by the reporting of incomplete and inconclusive data on baseline bone mineral density (BMD) in patients with stable COPD receiving long-term, regular treatment with ICSs in published studies. Baseline BMD data were available for a subgroup of 658 patients from the TORCH study; these data demonstrated a high prevalence of osteoporosis at baseline in stable COPD patients, and no significant difference was observed in the risk of developing osteoporosis and/or bone fractures after 3 years of therapy with fluticasone propionate alone versus placebo. ${ }^{9}$

Two meta-analyses on the risk of bone fractures with ICSs in COPD patients have been published to date, and, unlike in the BMD-evaluable patients of the TORCH study, both reported an increased likelihood of bone fractures in patients receiving ICSs. ${ }^{10,11}$ Yet, only one of these metaanalyses produced a result with statistical significance $(P=0.04$ for a relative increase of more than $20 \%$ in the likelihood of bone fractures in COPD patients receiving
ICSs), ${ }^{10}$ and both analyses were associated with a number of inherent limitations. The most recent systematic review on the role of ICSs in the long-term treatment of COPD patients was conducted by the Cochrane Collaboration group and concluded that, in long-term studies in which the effect of ICSs on bone density was measured, no notable effects on bone density and bone fractures were apparent during a 3-year follow-up period. ${ }^{12}$ This observation, however, was based on a small number of studies.

Given the mixed results obtained in previous metaanalyses and reviews on this topic, and the limitations associated with each, further exploration of the association between ICS use and bone fractures in COPD is necessary. The aim of our narrative review was to measure the risk of bone fractures in patients with COPD enrolled in long-term (at least 12 months' duration) randomized controlled trials (RCTs) of inhaled glucocorticoids alone versus placebo. We chose not to include studies using a combination of glucocorticoids and LABAs or LAMAs because of their potential effects on bone metabolism. ${ }^{13-19}$

\section{Methods \\ Search strategy}

A targeted, structured literature search was conducted using the PubMed database (NCBI, Bethesda MD, USA) using the search terms ["inhaled corticosteroids" and "COPD"] and ["bone mineral density" OR "hip fractures" OR "spinal fractures" OR "bone fracture(s)" OR "bone loss" OR "osteoporosis" OR "corticosteroid osteoporosis" OR "bone densitometry" OR "bone metabolism"]. The search was restricted to capture only full manuscripts published in English. Publications reporting the results of RCTs studying the long-term ( $\geq 12$ months) use of ICS alone versus placebo in patients with stable COPD (no documented exacerbation history) were selected by two investigators, Fabio Arpinelli and Maria Sandra Magnoni.

COPD studies using agents other than ICSs (eg, an ICS/ LABA combination) were excluded due to the potential effects of other agents on bone metabolism. Observational studies were excluded due to the potential inclusion of confounding variables in populations retrieved from health databases.

\section{Data extraction}

Key data were extracted from all eligible studies by a single investigator. Data on the following aspects of the studies were collected: study design variables (number of patients, 
length of ICS treatment); patient characteristics (age, gender, previous therapies, smoking, ethnicity, bone fractures, and BMD where available); and outcomes of interest.

\section{Results}

\section{Search results}

A total of 128 studies reported RCTs of patients with stable COPD published as full papers in English. These studies were filtered further to include those lasting between 12 and 48 months $(n=32)$ and to include only those that compared ICS with placebo $(n=17)$, giving a final total of 17 studies (Figure 1). These 17 studies were chosen for inclusion in our review (Table 1).

The ICSs used in each study were as follows: budesonide in six studies; ${ }^{20-25}$ fluticasone propionate in five studies; ${ }^{9,26-29}$ mometasone furoate in three studies; ${ }^{30-32}$ beclomethasone dipropionate, ${ }^{33}$ triamcinolone acetonide, ${ }^{34}$ and fluticasone furoate ${ }^{35}$ in one study each. Bone density was reported for subsets of patients in two studies, ${ }^{21,34}$ and bone fractures were reported for six studies. $9,21,26,30,31,35$ The majority of the identified RCTs were conducted in European countries only (10/17).

\section{Patient characteristics}

The proportion of males was higher than females in all included studies (male:female ratio range 1.08-6.21) and two studies enrolled only males. ${ }^{22,26}$ Mean age ranged from 46 to 67.6 years across all treatment arms in all studies.

\section{Bone mineral density}

Baseline and 3-year BMD data of the hip and lumbar spine were published by Ferguson et al for a subset of 658 American patients from the TORCH population $(n=6,184)$. At baseline, $18 \%$ of men and $30 \%$ of women had osteoporosis; when based on BMD assessment, osteopenia was present in $42 \%$ and $41 \%$ of men and women, respectively. After 3 years of treatment, changes in BMD at the hip and lumbar spine were small, and no significant difference between fluticasone propionate and placebo was found $(-2.9 \%$ and $-3.1 \%$, respectively). The incidence of bone fractures was also low and similar for all treatments (5.1-6.3\% across all arms). ${ }^{36}$

BMD was also measured in a sample of 194 patients (102 receiving budesonide and 92 in the placebo arm) in the EUROSCOP study. There was a significant change over time and no significant effect of treatment on BMD, except for a small, significant difference at the femoral trochanter (BMD decline in the femoral trochanter was $0.38 \%$ in the placebo arm and $0.04 \%$ in the budesonide arm $[P=0.02]) .^{21}$

Of the 1,116 patients of The Lung Health Study, BMD data for the lumbar spine and femur were taken for 412 patients. No significant differences were detected at baseline. After 3 years, the BMD of lumbar spine and the

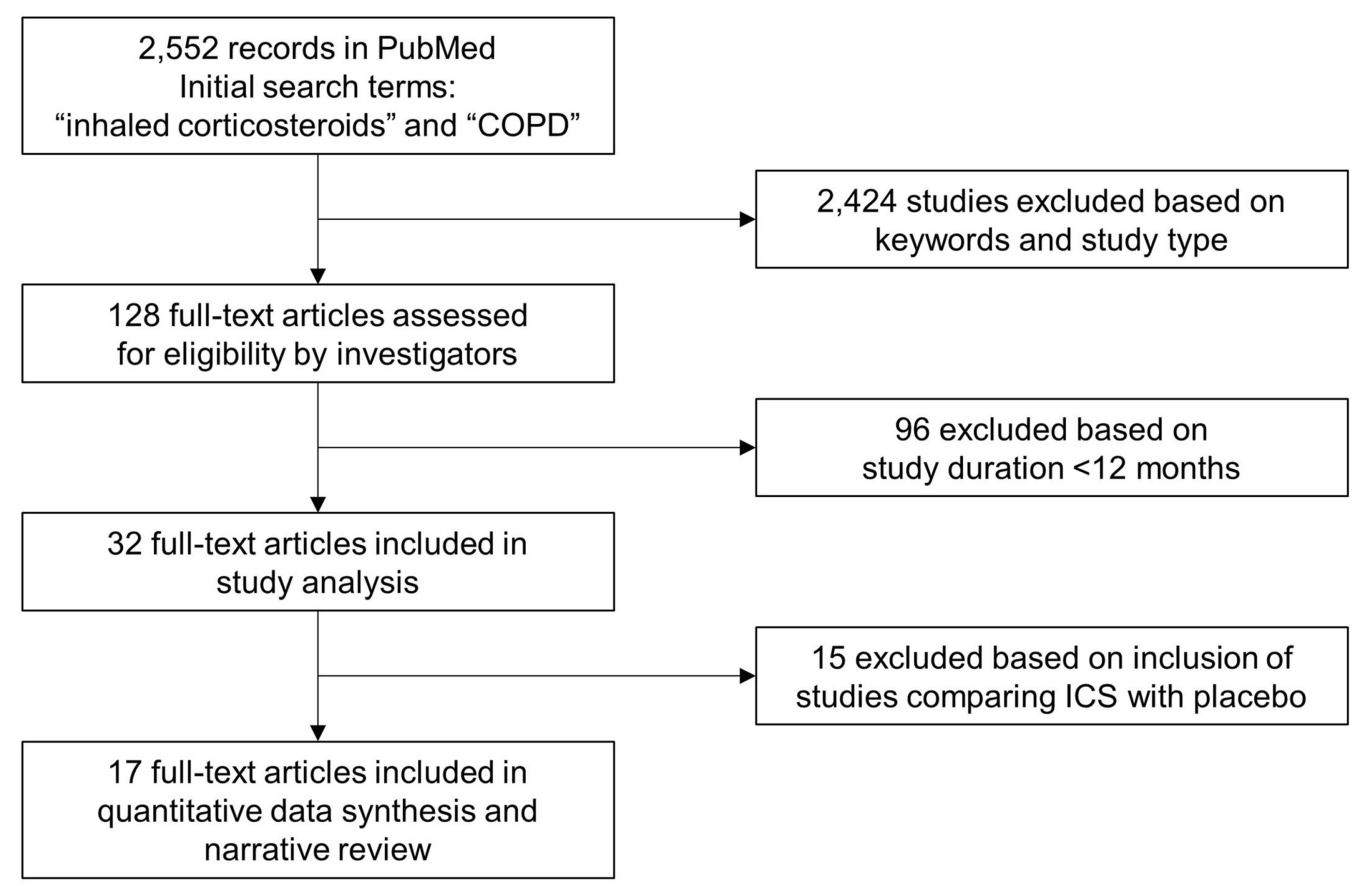

Figure I Flow chart of study selection. 


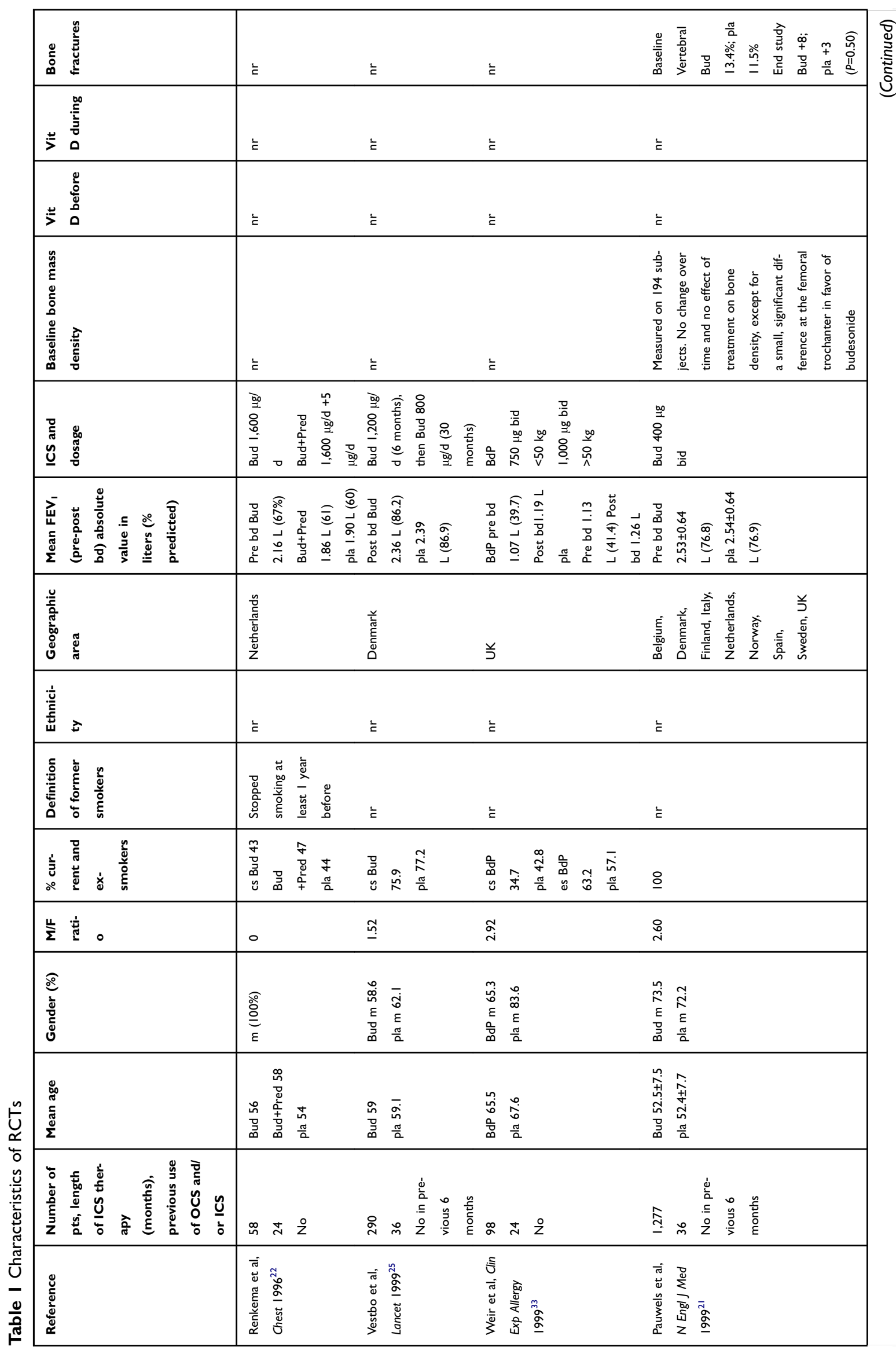




\begin{tabular}{|c|c|c|c|c|}
\hline 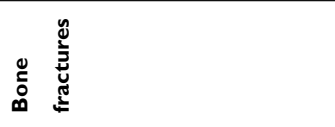 & $\grave{\Xi}$ & 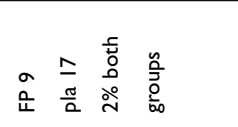 & 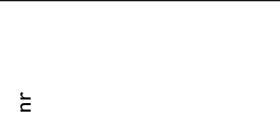 & $\grave{\Xi}$ \\
\hline 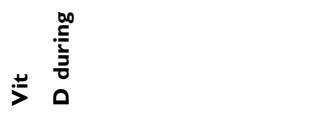 & $\grave{E}$ & $\grave{c}$ & 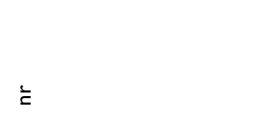 & 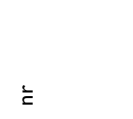 \\
\hline 晜 & $\grave{E}$ & $\grave{E}$ & $\grave{t}$ & $\grave{I}$ \\
\hline 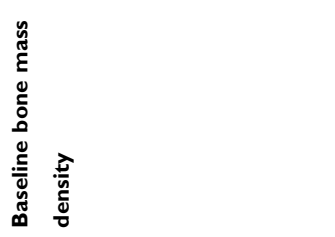 & 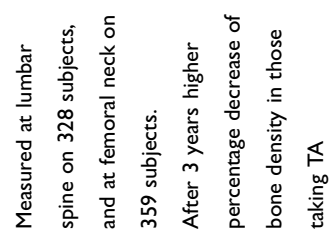 & 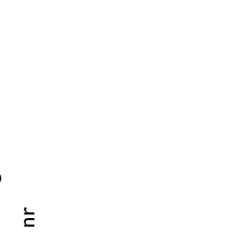 & $\bar{t}$ & $\grave{E}$ \\
\hline 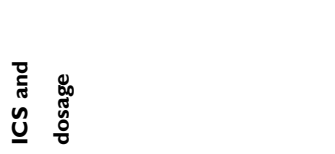 & 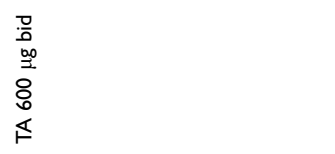 & 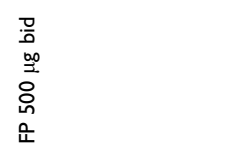 & 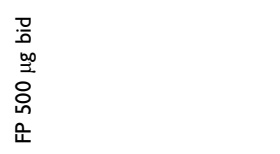 & 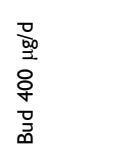 \\
\hline 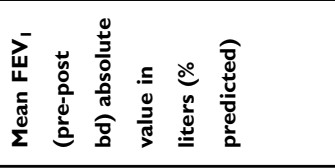 & 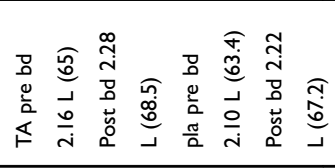 & 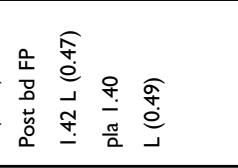 & 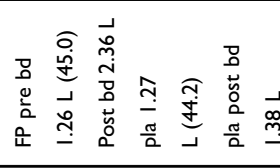 & 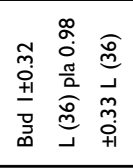 \\
\hline 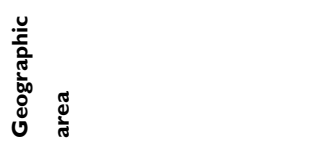 & 孚 & J & 兰 & 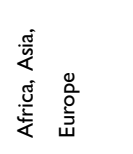 \\
\hline 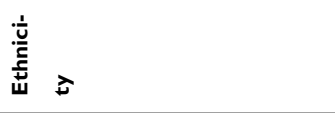 & 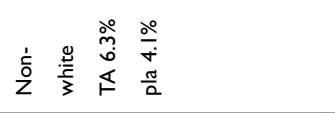 & $\grave{E}$ & 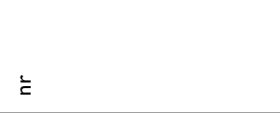 & 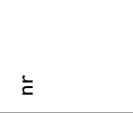 \\
\hline 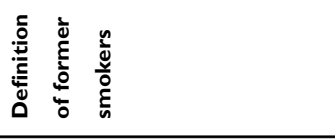 & 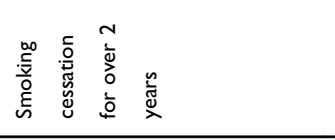 & 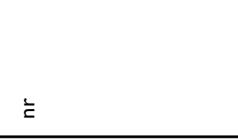 & 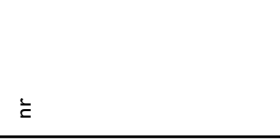 & 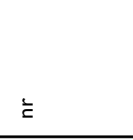 \\
\hline 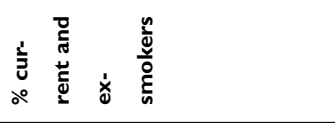 & 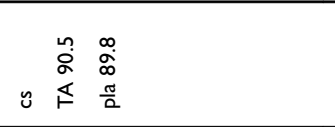 & 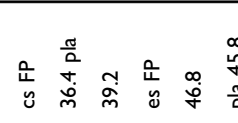 & 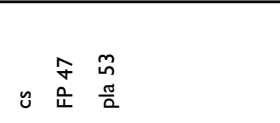 & 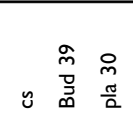 \\
\hline 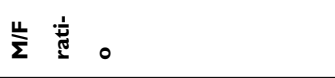 & $\stackrel{R}{?}$ & 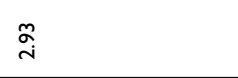 & $\bar{i}$ & $\stackrel{\vec{m}}{i}$ \\
\hline 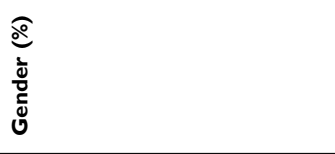 & 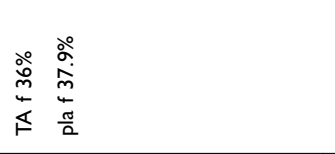 & 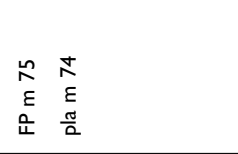 & $\begin{array}{ll}R & n \\
E & E \\
E & E \\
0 & \frac{\pi}{2} \\
\end{array}$ & 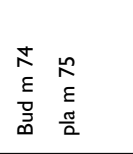 \\
\hline 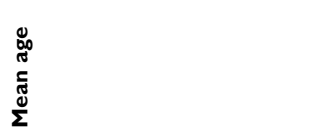 & 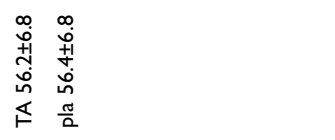 & 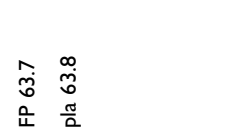 & 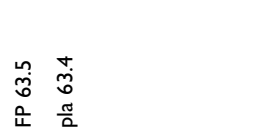 & 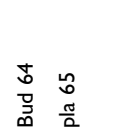 \\
\hline 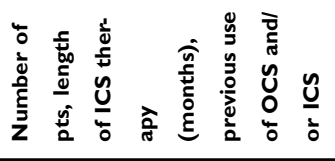 & 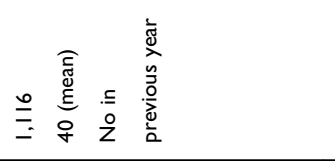 & 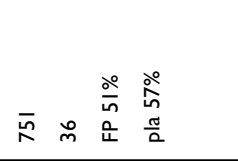 & 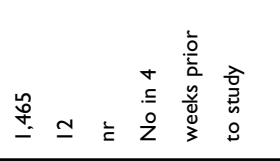 & 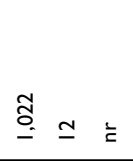 \\
\hline 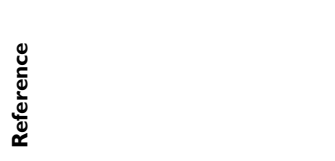 & 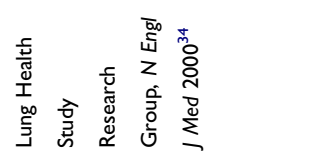 & 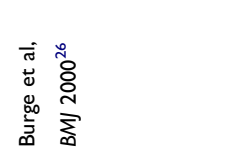 & 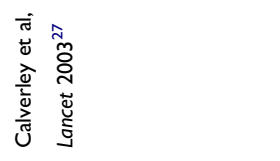 & 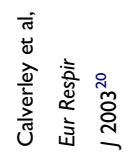 \\
\hline
\end{tabular}




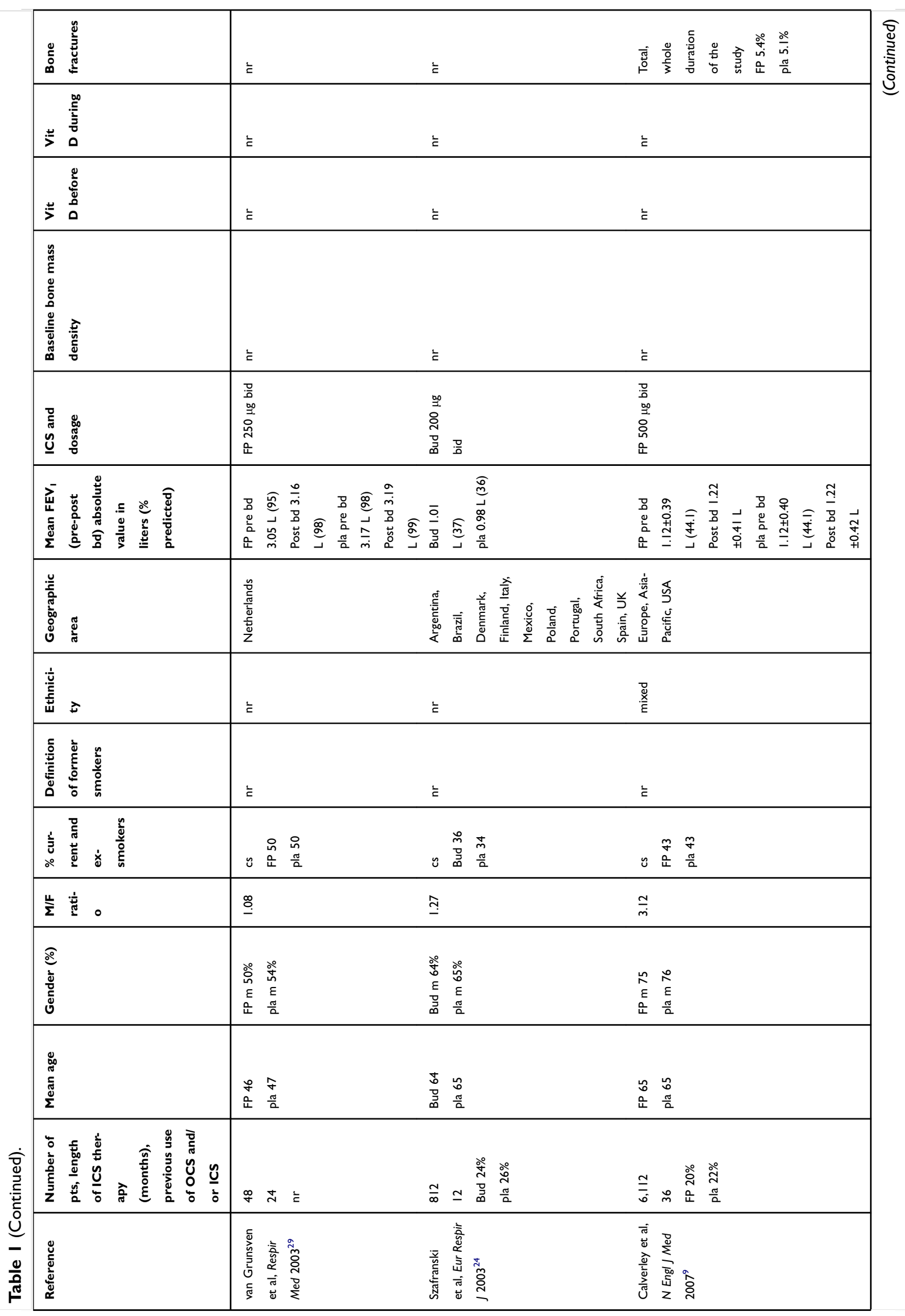




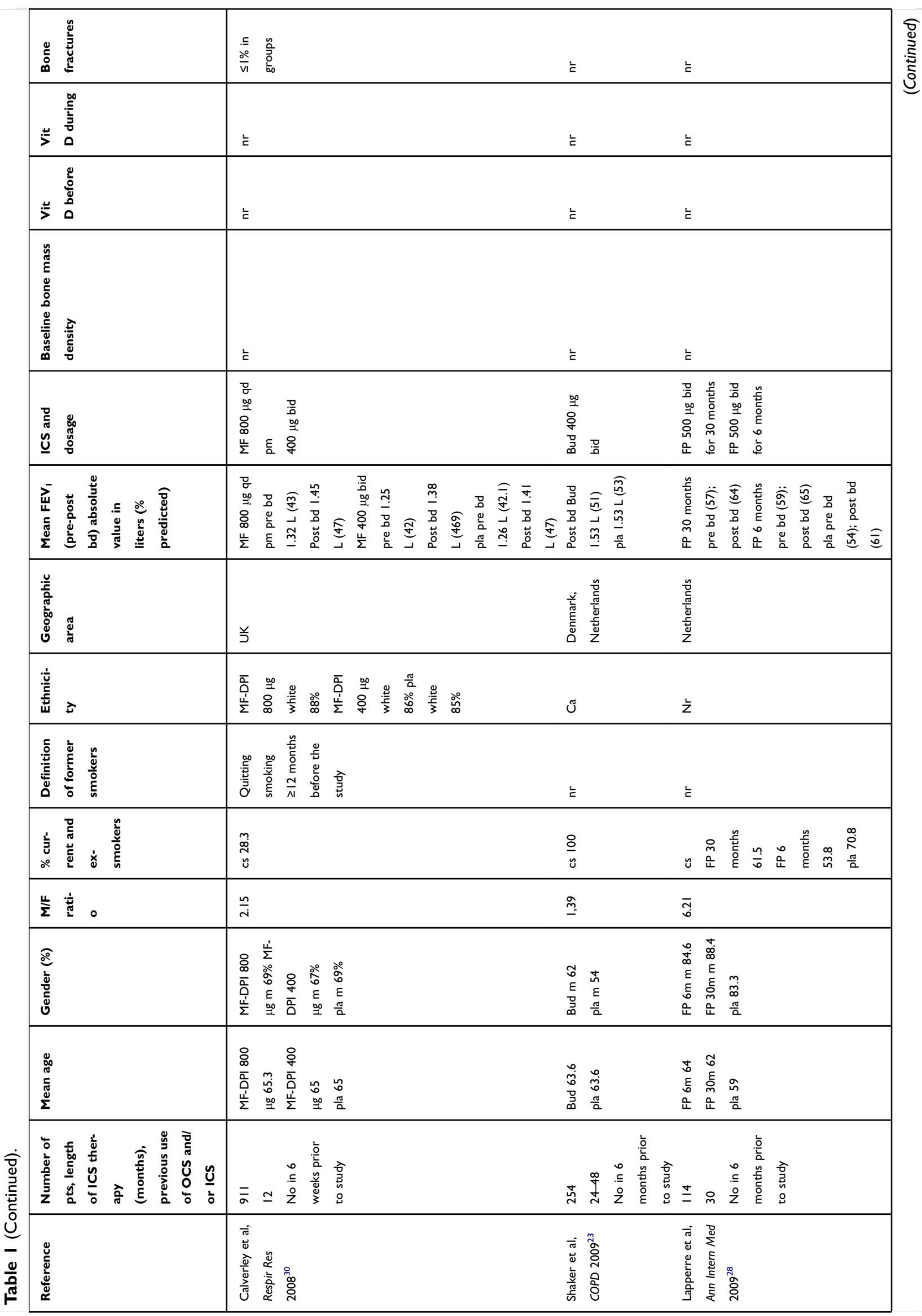




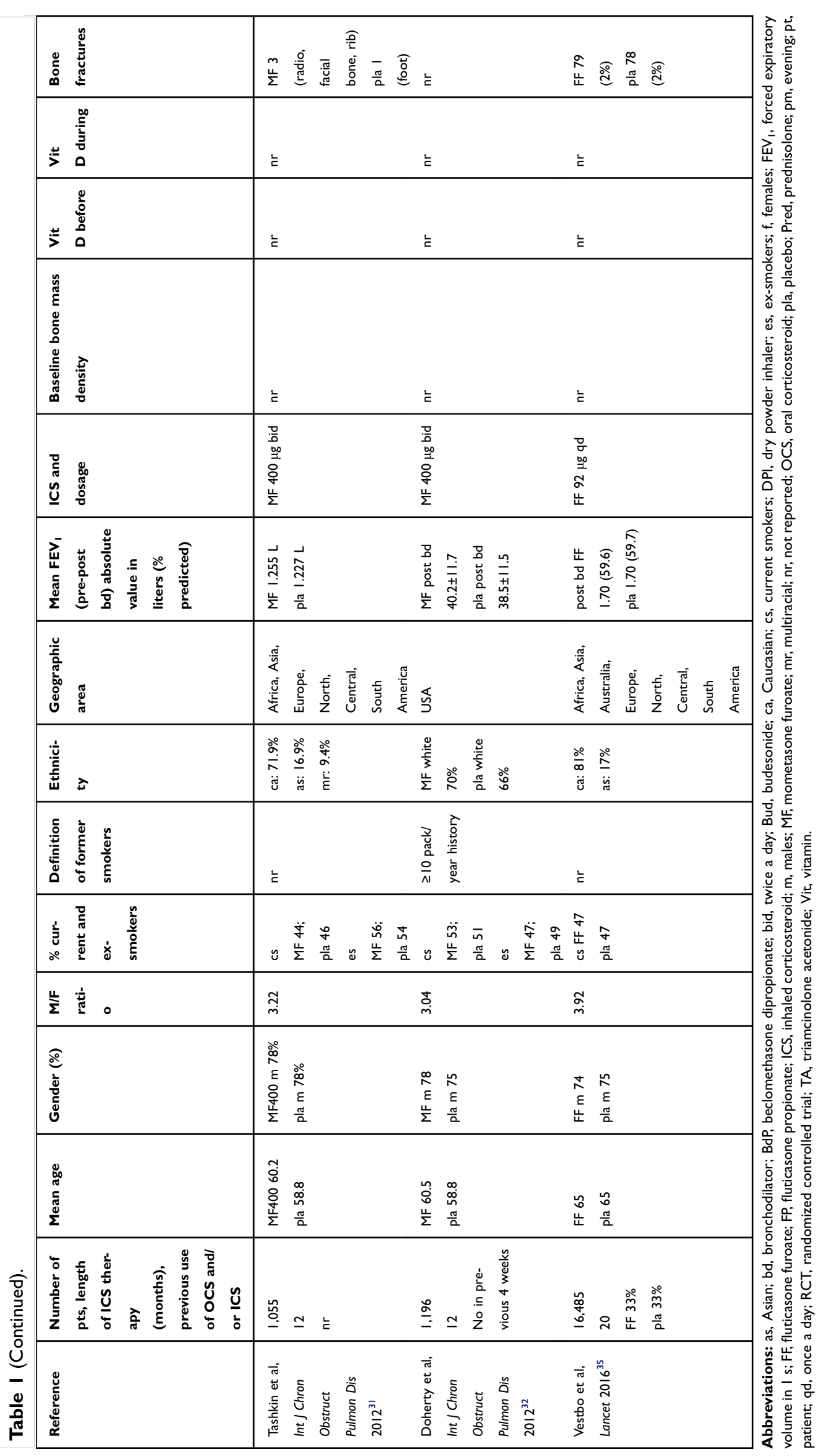


femur were significantly lower in the triamcinolone arm ( $P=0.007$ and $P<0.001$, respectively). ${ }^{34}$

\section{Incidence of bone fractures}

Generally speaking, no differences were found between the numbers of bone fractures reported among patients receiving an ICS versus placebo. Pauwels et al found no significant differences in the development of new fractures with budesonide and placebo over a treatment period of 3 years ( $\mathrm{n}=8$ vs $\mathrm{n}=3 ; P=0.50$ ) in 185 female and 468 male patients. ${ }^{21}$ Similarly, in the TORCH study, the incidence of fractures was $5.4 \%$ in the fluticasone propionate arm and $5.1 \%$ in the placebo arm, and this difference was not significant. $^{9}$

In the ISOLDE study, fractures were reported to have occurred in $4.6 \%$ of 370 patients receiving placebo and $2.4 \%$ of 372 patients receiving fluticasone propionate. ${ }^{26}$ Calverley et al found that the incidence of bone fractures among patients treated with mometasone and placebo was lower than $1 \%$ each. $^{30}$ Tashkin et al also reported an incidence of fractures lower than $1 \%$ with both mometasone and placebo. ${ }^{31}$ In the SUMMIT study, Vestbo et al reported 79 bone fractures with fluticasone furoate and 78 with placebo, amounting to an incidence of $2 \%$ in both groups. ${ }^{35}$

\section{Discussion}

Numerous factors contribute to decreased BMD and an increased likelihood of bone fractures in patients with COPD. First, the systemic chronic inflammation present in patients with stable COPD may have a direct local effect on bone homeostasis. ${ }^{37}$ For example, the levels of inflammatory cytokines, such as interleukin (IL)-1 $\beta$, IL-6, and tumor necrosis factor (TNF)- $\alpha,{ }^{38}$ are increased in the blood of patients with stable COPD and may upregulate bone resorption by stimulating osteoclast development. ${ }^{39}$ Hypogonadism is also relatively common in male patients with $\mathrm{COPD},{ }^{40}$ and if untreated can reduce the anabolic stimulus on formation of bone, as well as weakening skeletal muscle and limiting physical activity. ${ }^{41}$ Moreover, the bone resorption marker collagen type I $\beta$ isomerized $\mathrm{C}$-terminal telopeptide increases significantly in patients with COPD during exacerbation $(P<0.01$ compared with stable patients and $P<0.001$ compared with healthy volunteers). ${ }^{42}$ This indicates that COPD exacerbation may have detrimental effects on bone, and this is thought to be due to the intensification of characteristic disease symptoms such as inflammation, hypoxia, and oxidative stress during exacerbations. ${ }^{42}$ Inhaled ICSs may also disrupt bone homeostasis and induce osteoporosis $^{6}$ by reducing osteoblastogenesis from bone marrow mesenchymal cells, ${ }^{43}$ inducing osteoblast apoptosis by the production of reactive oxygen species, ${ }^{44}$ and by the suppression of osteoclastogenesis. ${ }^{45}$

Two previous meta-analyses have highlighted an increased relative risk of bone fractures in COPD patients receiving long-term treatment with ICSs. The first was designed to study the dose-response relationship between ICS use and the bone fracture risk, but also included patients with asthma and studied non-vertebral fractures only. This analysis found an increased relative risk of bone fractures of $12 \%$ for each $1,000 \mu \mathrm{g}$ (beclomethasone dipropionate equivalent) increase in daily ICS dose, though this result was not significant $(95 \%$ confidence interval [CI] 1.00-1.26). Furthermore, this meta-analysis was limited by the involvement of only five case-control studies, two of which used the same databases, a lack of subgroup analysis, and substantial heterogeneity. ${ }^{11}$

The second meta-analysis by Loke et al was based on 16 RCTs and 7 observational studies. ${ }^{10}$ Unlike the first, this analysis evaluated all types of bone fractures. The authors found that ICS exposure was significantly $(P=0.04)$ associated with a relative increase of more than $20 \%$ in the likelihood of bone fractures in patients with COPD receiving ICSs in RCTs. ${ }^{10}$ The number needed to harm was estimated to be 83 over a 3-year ICS treatment period based on the $5.1 \%$ bone fracture rates in the salmeterol and placebo arms of the TORCH trial. ${ }^{36}$ Again, the authors of this analysis reported some limitations of their study, such as the use of data from unpublished, non-peer reviewed company reports. Moreover, most of the RCTs included did not use specific methods to define and report the bone fractures, and it is possible that misclassification or underdiagnosis occurred. The timing of fractures with relation to the use of ICSs was also not reported, and results may have been affected by the inclusion of patients who received ICSs before joining their trial and the receipt of oral glucocorticoids by some control group patients on study.

The statistical significance of the outcomes of these analyses is inconsistent and subject to a degree of uncertainty in that the established $P$-values and CIs lie close to the significance threshold in both cases $(P=0.04$, significant; $95 \%$ CI $1.00-1.26$, non-significant).$^{10,11}$ The limitations associated with these analyses and their confounding results, along with the subsequent review on the topic by 
the Cochrane Collaboration group based on a narrow scope of studies, highlight the need to further explore this potential relationship.

Some studies in the real life literature, however, provide conflicting results on the impact of ICSs on fracture risk. For example, a retrospective cohort study conducted using a large UK primary care database demonstrated that while users of inhaled ICSs have an increased risk of fracture, this excess risk may be associated with the underlying respiratory disease more than the medicines used to treat it. ${ }^{46}$ Meanwhile, a large case-control study within the Dutch PHARMO-RLS database found that patients using inhaled ICSs did not have an increased risk of fracture after adjusting for underlying disease severity. ${ }^{47}$

We report the results of a narrative review of all published RCTs comparing long-term (at least 12 months) treatment with an ICS alone versus placebo in patients with stable COPD. Our aim was to study the potential association between treatment with ICSs and risk of bone fractures in patients with COPD in the relevant literature; however, none of the identified RCTs were specifically designed to measure the risk of bone fractures. This is reflected in the duration of the studies (12 months to 48 months), which was not calculated with the aim of observing bone-related endpoints in mind. Instead, these studies investigated mainly respiratory and mortality endpoints.

Overall, we found missing, incomplete, or contradictory data on changes in BMD and bone fractures in the identified studies. When data were collected on changes in BMD and fractures, they were reported in summary per treatment group and were not presented individually for males and females. Given the increased incidence of osteoporosis and increased fracture risk in postmenopausal women compared with men of a similar age, ${ }^{48}$ and considering the general age of patients in the RCTs identified in our review, it would indeed be helpful if gender-specific data were reported for these outcomes.

With oral glucocorticoid therapy, increased fracture risk is frequently seen within the first three to six months. ${ }^{49}$ However, data have been reported that suggest how patients taking oral glucocorticoid therapy may still have a greater risk of fracture compared with untreated patients with a similar BMD, as measured by dual X-ray absorptiometry. ${ }^{50}$ Although inhaled ICSs and oral glucocorticoids are different, these data suggest that glucocorticoid-induced fracture risk may, in fact, be independent of BMD. ${ }^{8}$
Only a fraction of patients in each study had measurements of bone density, if any, and baseline bone density was rarely measured. As BMD is an important factor in bone strength, such measurements would be useful for the accurate correlation of COPD treatment via ICSs with bone weakening. ${ }^{51}$

A potential limitation of our review is that it focused solely on comparisons of ICS versus placebo and did not include any data from studies of ICS-/bronchodilator combinations. Dual therapies are recommended for the treatment of COPD rather than ICS monotherapy, and so inclusion of studies investigating dual therapy could have provided a wider pool of BMD data relevant to everyday practice. Owing to the inconsistent results obtained from previous literature reviews on the association between ICS use and fracture risk in patients with COPD and the potential effects of LAMAs or LABAs on bone metabolism, such studies were excluded from our review to facilitate a stricter focus on the potential effects of ICSs on bone metabolism as a means of investigating this relationship in more detail.

We found that information on the presence of bone fractures was reported in only a few of the RCTs identified. In addition, these studies lacked adequate information on the main risk factors that may affect BMD and/or bone fractures (Table 2). For example, tobacco smoking is an

Table 2 Main risk factors that may affect bone mineral density and/or the risk of bone fractures

\begin{tabular}{|l|}
\hline Established: \\
\hline Age \\
Gender \\
Ethnicity \\
Family history \\
Genes \\
Smoking \\
Vitamin D serum levels \\
Body composition \\
Physical activity \\
Menopause and hypogonadism \\
Comorbidities (diabetes mellitus) \\
Drugs (glucocorticoids, thiazide diuretics, statins, sex steroids, \\
antidiabetic agents, acid-reducing drugs, selective serotonin reup- \\
take inhibitors, heparin, beta 2 adrenergic \\
Systemic inflammation \\
Controversial: \\
Alcohol use \\
\hline
\end{tabular}

Note: Data from references. ${ }^{8,13-19,37,39-41,48-50,52-54,56-60}$ 
important risk factor for osteoporosis, associated with increased rates of vertebral and hip fractures. ${ }^{52-55}$ Yet, data comparing the risk of bone fractures between current smokers and former smokers are not reported. Likewise, the degree of baseline physical activity of the patients with COPD is not given; physical activity is a risk factor for osteoporosis and may also increase the risk of instability and falls, and, consequently, of bone fractures. ${ }^{56}$ Discussion of the rates of bone fracture reported across the identified RCTs is also limited by the lack of a standardized definition of the term "bone fracture" and the provision of minimal information on fracture locations and impact across the studies.

Many of the reviewed studies also did not report data on important prior/concomitant therapies and supplements relevant to bone. For instance, data on the intake of oral and/or parenteral glucocorticoids, which are recommended for the treatment of moderate-to-severe COPD exacerbations and can influence osteoporosis, ${ }^{2}$ prior to and during the study are not reported. Furthermore, no data on the intake of vitamin D supplements, with or without calcium, were provided..$^{9,21,26,30,31,35}$ The components of diet (such as alcohol consumption), duration of sun exposure, and comorbidities known to modulate the risk of osteoporosis, like diabetes mellitus, were also missing. ${ }^{57-65}$

In conclusion, the relationship between long-term ICS use and the risk of bone fractures in patients with stable COPD remains unclear, due to data deficiencies and the use of inconsistent terminology across the literature studied. However, the development of future RCTs specifically designed to study the association between ICSs and bone fractures would represent an important step toward fully elucidating the nature of this uncertain relationship. Such studies should consider the limitations of previous COPD studies reporting bone outcomes outlined in this review, including the need to capture important patient baseline information, such as gender, age, BMI, smoking status, and comorbidities, such as the presence of diabetes.

\section{Abbreviation list}

BMD, bone mineral density; CI, confidence interval; COPD, chronic obstructive pulmonary disease; ICS, inhaled corticosteroid; IL, interleukin; LABA, longacting 32 -adrenergic agonist; LAMA, long-acting muscarinic antagonist; RCT, randomized controlled trial; TNF, tumor necrosis factor.

\section{Acknowledgments}

Writing assistance for this manuscript was provided by Matthew Hallam, MSc(Res), of Gardiner-Caldwell Communications, an Ashfield Healthcare Communications company, part of UDG Healthcare plc, which was funded by GlaxoSmithKline plc (GSK) in compliance with Good Publication Practice 3 ethical guidelines (Battisti et al Ann Intern Med 2015; 163:461-4). The authors would like to thank Maria Sandra Magnoni for her contributions to documenting the methodology followed in conducting this review, and both Fabio Arpinelli and Maria Sandra Magnoni for their identification of studies for inclusion. The paper was prepared using published data. The authors have not received any fee.

\section{Author contributions}

All authors contributed to data analysis, drafting or revising the article, gave final approval of the version to be published, and agree to be accountable for all aspects of the work.

\section{Disclosure}

FA is an employee of GSK and owns stock in GSK. LS was an employee of GSK at the time of preparation of the manuscript. GC reports grants, personal fees, and non-financial support from Astra Zeneca, Boehringer Ingelheim, GSK, and Menarini Group, and grants from AlfaSigma, outside the submitted work. The authors report no other conflicts of interest in this work.

\section{References}

1. Abdool-Gaffar MS, Ambaram A, Ainslie GM, et al. Guideline for the management of chronic obstructive pulmonary disease-2011 update. S Afr Med J. 2011;101(1 Pt 2):63-73.

2. Global Initiative for Chronic Obstructive Lung Disease. Global strategy for the diagnosis, management and prevention of chronic obstructive pulmonary disease (2018 report) [Internet]. Available from: https://gold copd.org/wp-content/uploads/2017/11/GOLD-2018-v6.0-FINALrevised-20-Nov_WMS.pdf. Accessed April 6, 2018.

3. Miravitlles M, Vogelmeier C, Roche N, et al. A review of national guidelines for management of COPD in Europe. Eur Respir J. 2016;47 (2):625-637. doi:10.1183/13993003.01170-2015

4. O'Donnell DE, Hernandez P, Kaplan A, et al. Canadian Thoracic Society recommendations for management of chronic obstructive pulmonary disease - 2008 update - highlights for primary care. Can Respir J. 2008;15(Suppl A):1a-8a.

5. Qaseem A, Wilt TJ, Weinberger SE, et al. Diagnosis and management of stable chronic obstructive pulmonary disease: a clinical practice guideline update from the American College of Physicians, American College of Chest Physicians, American Thoracic Society, and European Respiratory Society. Ann Intern Med. 2011;155 (3):179-191. doi:10.7326/0003-4819-155-3-201108020-00008 
6. Chee C, Sellahewa L, Pappachan JM. Inhaled corticosteroids and bone health. Open Respir Med J. 2014;8:85-92. doi:10.2174/ 1874306401408010085

7. Liu WT, Kuo HP, Liao TH, et al. Low bone mineral density in COPD patients with osteoporosis is related to low daily physical activity and high COPD assessment test scores. Int J Chron Obstruct Pulmon Dis. 2015;10:1737-1744.

8. Sutter SA, Stein EM. The skeletal effects of inhaled glucocorticoids. Curr Osteoporos Rep. 2016;14(3):106-113. doi:10.1007/s11914-016-0308-1

9. Calverley PM, Anderson JA, Celli B, et al. Salmeterol and fluticasone propionate and survival in chronic obstructive pulmonary disease. N Engl J Med. 2007;356(8):775-789. doi:10.1056/NEJMc063190

10. Loke YK, Cavallazzi R, Singh S. Risk of fractures with inhaled corticosteroids in COPD: systematic review and meta-analysis of randomised controlled trials and observational studies. Thorax. 2011;66(8):699-708. doi:10.1136/thx.2011.160028

11. Weatherall M, James K, Clay J, et al. Dose-response relationship for risk of non-vertebral fracture with inhaled corticosteroids. Clin Exp Allergy. 2008;38(9):1451-1458. doi:10.1111/j.1365-2222.2008.03029.x

12. Yang IA, Fong KM, Sim EH, Black PN, Lasserson TJ. Inhaled corticosteroids for stable chronic obstructive pulmonary disease. Cochrane Database Syst Rev. 2007;18(2):CD002991.

13. Arai M, Nagasawa T, Koshihara Y, Yamamoto S, Togari A. Effects of beta-adrenergic agonists on bone-resorbing activity in human osteoclast-like cells. Biochim Biophys Acta. 2003;1640(2-3):137-142. doi:10.1016/S0167-4889(03)00042-9

14. Bonnet N, Brunet-Imbault B, Arlettaz A, et al. Alteration of trabecular bone under chronic beta2 agonists treatment. Med Sci Sports Exerc. 2005;37(9):1493-1501. doi:10.1249/01.mss.0000177592.82507.95

15. Gonnelli S, Caffarelli C, Maggi S, et al. Effect of inhaled glucocorticoids and beta(2) agonists on vertebral fracture risk in COPD patients: the EOLO study. Calcif Tissue Int. 2010;87(2):137-143. doi:10.1007/s00223-010-9392-x

16. Shi Y, Oury F, Yadav VK, et al. Signaling through the M(3) muscarinic receptor favors bone mass accrual by decreasing sympathetic activity. Cell Metab. 2010;11(3):231-238. doi:10.1016/j.cmet.2010.01.005

17. Ternes S, Trinkaus K, Bergen I, et al. Impact of acetylcholine and nicotine on human osteoclastogenesis in vitro. Int Immunopharmacol. 2015;29(1):215-221. doi:10.1016/j.intimp.2015.10.008

18. Veldhuis-Vlug AG, Oei L, Souverein PC, et al. Association of polymorphisms in the beta- 2 adrenergic receptor gene with fracture risk and bone mineral density. Osteoporos Int. 2015;26(7):2019-2027. doi:10.1007/s00198-015-3087-0

19. Veldhuis-Vlug AG, Tanck MW, Limonard EJ, et al. The effects of beta-2 adrenergic agonist and antagonist on human bone metabolism: a randomized controlled trial. Bone. 2015;71:196-200. doi:10.1016/j. bone.2014.10.024

20. Calverley PM, Boonsawat W, Cseke Z, Zhong N, Peterson S, Olsson H. Maintenance therapy with budesonide and formoterol in chronic obstructive pulmonary disease. Eur Respir J. 2003;22 (6):912-919. doi:10.1183/09031936.03.00027003

21. Pauwels RA, Lofdahl CG, Laitinen LA, et al. Long-term treatment with inhaled budesonide in persons with mild chronic obstructive pulmonary disease who continue smoking. European Respiratory Society Study on Chronic Obstructive Pulmonary Disease. N Engl J Med. 1999;340 (25):1948-1953. doi:10.1056/NEJM199905133401909

22. Renkema TE, Schouten JP, Koeter GH, Postma DS. Effects of long-term treatment with corticosteroids in COPD. Chest. 1996;109 (5):1156-1162. doi:10.1378/chest.109.5.1156

23. Shaker SB, Dirksen A, Ulrik CS, et al. The effect of inhaled corticosteroids on the development of emphysema in smokers assessed by annual computed tomography. Copd. 2009;6(2):104-111. doi:10.1080/ 15412550902772593

24. Szafranski W, Cukier A, Ramirez A, et al. Efficacy and safety of budesonide/formoterol in the management of chronic obstructive pulmonary disease. Eur Respir J. 2003;21(1):74-81.
25. Vestbo J, Sorensen T, Lange P, Brix A, Torre P, Viskum K. Long-term effect of inhaled budesonide in mild and moderate chronic obstructive pulmonary disease: a randomised controlled trial. Lancet. 1999;353(9167):1819-1823. doi:10.1016/S0140-6736(98)09449-5

26. Burge PS, Calverley PM, Jones PW, Spencer S, Anderson JA, Maslen TK. Randomised, double blind, placebo controlled study of fluticasone propionate in patients with moderate to severe chronic obstructive pulmonary disease: the ISOLDE trial. BMJ. 2000;320 (7245):1297-1303. doi:10.1136/bmj.320.7245.1297

27. Calverley P, Pauwels R, Vestbo J, et al. Combined salmeterol and fluticasone in the treatment of chronic obstructive pulmonary disease: a randomised controlled trial. Lancet. 2003;361(9356):449-456. doi:10.1016/S0140-6736(03)12459-2

28. Lapperre TS, Snoeck-Stroband JB, Gosman MM, et al. Effect of fluticasone with and without salmeterol on pulmonary outcomes in chronic obstructive pulmonary disease: a randomized trial. Ann Intern Med. 2009;151(8):517-527. doi:10.7326/0003-4819-1518-200910200-00004

29. Van Grunsven P, Schermer T, Akkermans R, et al. Short- and long-term efficacy of fluticasone propionate in subjects with early signs and symptoms of chronic obstructive pulmonary disease. Results of the DIMCA study. Respir Med. 2003;97(12):1303-1312. doi:10.1016/j.rmed.2003.08.001

30. Calverley PM, Rennard S, Nelson HS, et al. One-year treatment with mometasone furoate in chronic obstructive pulmonary disease. Respir Res. 2008;9:73. doi:10.1186/1465-9921-9-73

31. Tashkin DP, Doherty DE, Kerwin E, et al. Efficacy and safety of a fixed-dose combination of mometasone furoate and formoterol fumarate in subjects with moderate to very severe COPD: results from a 52-week Phase III trial. Int J Chron Obstruct Pulmon Dis. 2012;7:43-55.

32. Doherty DE, Tashkin DP, Kerwin E, et al. Effects of mometasone furoate/formoterol fumarate fixed-dose combination formulation on chronic obstructive pulmonary disease (COPD): results from a 52-week Phase III trial in subjects with moderate-to-very severe COPD. Int $J$ Chron Obstruct Pulmon Dis. 2012;7:57-71. doi:10.2147/COPD.S27320

33. Weir DC, Bale GA, Bright P, Sherwood Burge P. A double-blind placebo-controlled study of the effect of inhaled beclomethasone dipropionate for 2 years in patients with nonasthmatic chronic obstructive pulmonary disease. Clin Exp Allergy. 1999;29(Suppl 2):125-128. doi:10.1046/j.1365-2222.1999.00021.x

34. Wise R, Connett J, Weinmann G, Scanlon P, Skeans M; Lung Health Study Research Group. Effect of inhaled triamcinolone on the decline in pulmonary function in chronic obstructive pulmonary disease. $N$ Engl J Med. 2000;343(26):1902-1909. doi:10.1056/ NEJM200012283432601

35. Vestbo J, Anderson JA, Brook RD, et al. Fluticasone furoate and vilanterol and survival in chronic obstructive pulmonary disease with heightened cardiovascular risk (SUMMIT): a double-blind randomised controlled trial. Lancet. 2016;387(10030):1817-1826. doi:10.1016/S0140-6736(16)30069-1

36. Ferguson GT, Calverley PMA, Anderson JA, et al. Prevalence and progression of osteoporosis in patients with COPD: results from the TOwards a Revolution in COPD Health study. Chest. 2009;136 (6):1456-1465. doi:10.1378/chest.08-3016

37. Nguyen TV, Center JR, Eisman JA. Osteoporosis in elderly men and women: effects of dietary calcium, physical activity, and body mass index. J Bone Miner Res. 2000;15(2):322-331. doi:10.1359/ jbmr.2000.15.9.1798

38. Barnes PJ. The cytokine network in chronic obstructive pulmonary disease. Am J Respir Cell Mol Biol. 2009;41(6):631-638. doi:10.1165/ rcmb.2009-0220TR

39. Debigare $\mathrm{R}$, Marquis $\mathrm{K}$, Cote $\mathrm{CH}$, et al. Catabolic/anabolic balance and muscle wasting in patients with COPD. Chest. 2003;124 (1):83-89. doi:10.1378/chest.124.1.83 
40. Balasubramanian V, Naing S. Hypogonadism in chronic obstructive pulmonary disease: incidence and effects. Curr Opin Pulm Med. 2012;18(2):112-117. doi:10.1097/MCP.0b013e32834feb37

41. Kamischke A, Kemper DE, Castel MA, et al. Testosterone levels in men with chronic obstructive pulmonary disease with or without glucocorticoid therapy. Eur Respir J. 1998;11(1):41-45. doi:10.1183/09031936.98.11010041

42. Stanojkovic I, Kotur-Stevuljevic J, Spasic S, et al. Relationship between bone resorption, oxidative stress and inflammation in severe COPD exacerbation. Clin Biochem. 2013;46(16-17):1678-1682. doi:10.1016/j.clinbiochem.2013.04.011

43. Georgiou KR, Hui SK, Xian CJ. Regulatory pathways associated with bone loss and bone marrow adiposity caused by aging, chemotherapy, glucocorticoid therapy and radiotherapy. Am J Stem Cells. 2012;1(3):205-224.

44. Almeida M, Han L, Ambrogini E, Weinstein RS, Manolagas SC. Glucocorticoids and tumor necrosis factor alpha increase oxidative stress and suppress Wnt protein signaling in osteoblasts. J Biol Chem. 2011;286(52):44326-44335. doi:10.1074/jbc.M111.283481

45. Kim HJ, Zhao H, Kitaura H, et al. Glucocorticoids suppress bone formation via the osteoclast. J Clin Invest. 2006;116(8):2152-2160. doi: $10.1172 / \mathrm{JCI} 28084$

46. van Staa TP, Leufkens HG, Cooper C. Use of inhaled corticosteroids and risk of fractures. $J$ Bone Miner Res. 2001;16(3):581-588. doi:10.1359/jbmr.2001.16.3.581

47. de Vries F, Pouwels S, Lammers JW, et al. Use of inhaled and oral glucocorticoids, severity of inflammatory disease and risk of hip/ femur fracture: a population-based case-control study. J Intern Med. 2007;261(2):170-177. doi:10.1111/j.1365-2796.2006.01754.x

48. Cawthon PM. Gender differences in osteoporosis and fractures. Clin Orthop Relat Res. 2011;469(7):1900-1905. doi:10.1007/s11999-0111780-7

49. van Staa TP, Leufkens HG, Cooper C. The epidemiology of corticosteroid-induced osteoporosis: a meta-analysis. Osteoporosis Int. 2002;13(10):777-787. doi:10.1007/s001980200108

50. van Staa TP, Laan RF, Barton IP, et al. Bone density threshold and other predictors of vertebral fracture in patients receiving oral glucocorticoid therapy. Arthritis Rheum. 2003;48(11):3224-3229. doi:10.1002/art.11283

51. Ammann P, Rizzoli R. Bone strength and its determinants. Osteoporos Int. 2003;14(Suppl 3):S13-S18. doi:10.1007/s00198002-1345-4

52. Bolton CE, Ionescu AA, Shiels KM, et al. Associated loss of fat-free mass and bone mineral density in chronic obstructive pulmonary disease. Am J Respir Crit Care Med. 2004;170(12):1286-1293. doi:10.1164/rccm.200406-754OC

53. Kiel DP, Zhang Y, Hannan MT, Anderson JJ, Baron JA, Felson DT. The effect of smoking at different life stages on bone mineral density in elderly men and women. Osteoporos Int. 1996;6(3):240-248. doi:10.1007/BF01622741
54. Law MR, Hackshaw AK. A meta-analysis of cigarette smoking, bone mineral density and risk of hip fracture: recognition of a major effect. BMJ. 1997;315(7112):841-846. doi:10.1136/ bmj.315.7112.841

55. Ortego-Centeno N, Munoz-Torres M, Jodar E, Hernandez-Quero J, Jurado-Duce A, De La Higuera Torres-Puchol J. Effect of tobacco consumption on bone mineral density in healthy young males. Calcif Tissue Int. 1997;60(6):496-500

56. Inoue D, Watanabe R, Copd OR. and osteoporosis: links, risks, and treatment challenges. Int $J$ Chron Obstruct Pulmon Dis. 2016;11:637-648. doi:10.2147/COPD.S79638

57. Aung K, Htay T. Thiazide diuretics and the risk of hip fracture. Cochrane Database Syst Rev. 2011;5(10):CD005185.

58. Berg KM, Kunins HV, Jackson JL, et al. Association between alcohol consumption and both osteoporotic fracture and bone density. Am J Med. 2008;121(5):406-418. doi:10.1016/j. amjmed.2007.12.012

59. Byreddy DV, Bouchonville MF 2nd, Lewiecki EM. Drug-induced osteoporosis: from Fuller Albright to aromatase inhibitors. Climacteric. 2015;18(Suppl 2):39-46. doi:10.3109/ 13697137.2015.1103615

60. Drake MT, Murad MH, Mauck KF, et al. Clinical review. Risk factors for low bone mass-related fractures in men: a systematic review and meta-analysis. J Clin Endocrinol Metab. 2012;97(6):1861-1870. doi:10.1210/jc.2011-3058

61. Guo M, Qu H, Xu L, Shi DZ. Tea consumption may decrease the risk of osteoporosis: an updated meta-analysis of observational studies. Nutr Res. 2017;42:1-10. doi:10.1016/j. nutres.2017.02.010

62. Liu J, Zhu LP, Yang XL, Huang HL, Ye DQ. HMG-CoA reductase inhibitors (statins) and bone mineral density: a meta-analysis. Bone. 2013;54(1):151-156. doi:10.1016/j.bone.2013.01.044

63. Moayeri A, Mohamadpour M, Mousavi SF, Shirzadpour E, Mohamadpour S, Amraei M. Fracture risk in patients with type 2 diabetes mellitus and possible risk factors: a systematic review and meta-analysis. Ther Clin Risk Manag. 2017;13:455-468. doi:10.2147/TCRM.S131945

64. Watts NB. Adverse bone effects of medications used to treat non-skeletal disorders. Osteoporos Int. 2017;28(10):2741-2746. doi:10.1007/s00198-016-3774-5

65. Zhang ZF, Yang JL, Jiang HC, Lai Z, Wu F, Liu ZX. Updated association of tea consumption and bone mineral density: A meta-analysis. Medicine (Baltimore). 2017;96(12):e6437. doi:10.1097/MD.0000000000006437
The International Journal of COPD is an international, peer-reviewed journal of therapeutics and pharmacology focusing on concise rapid reporting of clinical studies and reviews in COPD. Special focus is given to the pathophysiological processes underlying the disease, intervention programs, patient focused education, and self management protocols. This journal is indexed on PubMed Central, MedLine and CAS. The manuscript management system is completely online and includes a very quick and fair peer-review system, which is all easy to use. Visit http://www.dovepress.com/testimonials.php to read real quotes from published authors. 